\title{
Moda e metodologia: o Design como mediador
}

Fashion and methodology: the Design as a mediator

\section{Cyntia Tavares Marques de Queiroz}

Doutorado em Educação pela Universidade Federal do Ceará cyntiatavares@yahoo.com.br

\section{Aline Teresinha Basso}

Mestre pelo Programa de Pós-graduação em Artes Visuais, UFPB/UFPE alinebasso@gmail.com 


\title{
Moda e metodologia: o Design como mediador
}

\author{
Fashion and methodology: the Design as a mediator
}

\section{Cyntia Tavares Marques de Queiroz e Aline Teresinha Basso}

\section{Resumo}

O presente artigo propõe uma análise metodológica dos processos de desenvolvimento de coleções de moda, estabelecendo paralelos entre os caminhos utilizados pelo estilista e pelo designer. Apresenta as principais mudanças que os currículos dos cursos de moda do Brasil sofreram, ao migrarem para o campo do design, enfatizando os diferenciais estabelecidos na concepção dos produtos de moda. Para tanto, investiga o que consideramos a primeira metodologia para o desenvolvimento de coleções, por Doris Treptow, e estabelece paralelos com a metodologia de design de Bernd Löbach e com o Metaprojeto de Dijon de Moraes. Os resultados apontam semelhanças entre os processos metodológicos e ampliam suas possibilidades de uso. Dessa forma é possível perceber a legitimidade do método de Treptow para o design de moda, e sua facilidade de adequação ao mundo complexo com o qual o design trabalha nos dias de hoje.

Palavras- chave: Desenvolvimento de Coleção; Metodologia Projetual; Metaprojeto

\begin{abstract}
This article proposes a methodological analysis of the fashion collections development processes, comparing the designer and the stylist ways. It shows the main changes that the curricula of Brazil's fashion courses suffered, when they had to migrate to the design field, emphasizing the fashion design conception changes. For this, we investigate what we consider the first methodology for the development of fashion collections, Doris Treptow, and we compared it with the Bernd Lobach methodology and the Dijon de Moraes meta-project. The results show similarities between the methodological processes and extend their use possibilities. It was possible to realize the legitimacy of Treptow method for fashion design, and its suitability to the complex design world nowadays.
\end{abstract}

Keywords: Collection Development; Projetual methodology; Meta-project. 


\section{Introdução}

Desde que os cursos superiores de moda no Brasil foram obrigados, pelo Ministério da Educação (MEC), a migrar para o campo do design, em 2004, 138 bacharelados, dos 175 existentes em 2014, organizam-se para que esta transição possa ocorrer da melhor forma possível, considerando os desafios estruturais e de formação do corpo docente. Como defendemos que as diferenças entre os dois campos são potencializadas na disputa pelo seu domínio, com a notável presença de dominados, os estilistas, e dominantes, os designers, fica cada vez mais difícil estabelecermos as reais diferenças entre uma formação e outra.

Nosso artigo apresenta como recorte a análise de uma característica que predomina no design e que se constitui como uma das mais recorrentes explicações e justificativas de superioridade do novo campo, a existência de uma metodologia própria de concepção de produtos do vestuário, denominada de metodologia projetual.

Assim, com o propósito de traçarmos paralelos entre os caminhos metodológicos utilizados pelos estilistas e os designers no desenvolvimento das suas coleções de moda, apresentamos um breve histórico da formação de moda no país, destacando as metodologias utilizadas em cada uma das concepções formativas. Iniciamos nossa abordagem com Doris Treptow, pioneira na apresentação de um método que se adequava à formação do estilista e que, portanto, predominou no crucial momento de transição entre os dois currículos. A partir dela, estabelecemos paralelos com a metodologia de design de Bernd Löbach e com o Metaprojeto de Dijon de Moraes.

\section{A Formação em Moda no Brasil}

Apesar de termos registros da existência de escolas femininas que promoviam o ensino da moda na França do século XVII (LIPOVETSKY,1989), no Brasil a formação superior na área ocorreu tardiamente, em $1988^{1}$, na Faculdade de Santa Marcelina, em São Paulo.

Como a necessidade do profissional é anterior a esta data, as atividades relacionadas ao desenvolvimento de produtos para o vestuário foram desempenhadas por leigos e autodidatas com talento artístico e que, com o exercício da função,

\footnotetext{
${ }^{1}$ Aprovado pelo MEC em 1987, razão pela qual algumas referências trazem o ano de 1987, enquanto outras apresentam o ano de 1988, como o marco da formação em moda no Brasil.
} 
adquiriam conhecimentos empíricos. À época, apresentavam como princípio metodológico a realização de viagens internacionais, em busca de referências externas. Este fato nos explica muito sobre duas características dos cursos de graduação em moda, os seus vínculos, majoritariamente, com as faculdades de arte, pois o ofício estava nela baseado, e o olhar dos seus fundadores para as formações estrangeiras, de modo que as primeiras estruturas curriculares dialogavam pouco com as necessidades locais.

Outra característica dos primeiros cursos de moda é que herdaram para si a imagem de que se tratava de uma formação feminina e pouco intelectual. De acordo com Bonadio (2010), a desvalorização da moda enquanto campo está muito evidente no percurso de Gilda de Mello Souza. Após apresentar a tese intitulada "A Moda no século XIX: ensaio de sociologia estética", na Faculdade de Filosofia, Ciências e Letras da Universidade de São Paulo, em 1950, a autora gerou desconforto na maioria dos membros da academia, que consideraram o tema fútil, e o assunto de menor valor. Não havia o entendimento de que o seu trabalho se enquadrava às normas e aos critérios do campo científico e só foi possível publicá-lo em 1987, como “O Espírito das roupas - a Moda do século XIX”, constituindo-se uma obra de referência hoje no Brasil.

Souza (1987) lançou mão da história, da sociologia, da antropologia e da estética, em uma obra que revela, dentre outros aspectos, o caráter predominantemente feminino na prática social dos trabalhos de agulha. Para a autora, os homens rejeitavam os ornamentos, enquanto as mulheres criavam um estilo de existência por meio das suas modas e dos seus modos. Paralelamente, o discurso científico do século XIX apresentava a inferioridade feminina com base na biologia, contribuindo para reforçar uma imagem de futilidade atrelada ao campo.

Passados 28 anos, desde a criação do primeiro curso de moda no Brasil, que se ocupava da formação do estilista, houve alternância do campo e a formação passou a constituir o campo do design de moda ou, na terminologia de Christo (2013), o campo de produção de objetos do vestuário, no qual se legitima e consagra o designer, não mais o estilista. Neste contexto, não verificamos, historicamente, a relação entre o profissional do design e o feminino. Ao contrário, os seus grandes nomes pertenciam ao gênero masculino. Assim, não podemos deixar de refletir sobre o fato de que é justamente o designer que vai se colocar como dominante na polarização com o estilista, incluindo, entre as razões deste domínio, também as questões de gênero. Consideremos, 
além deste aspecto, o fato da formação em design ter surgido alguns anos antes da formação em moda e, portanto, apresentar um tempo maior de acúmulo de capital específico.

Esta migração ocorreu oficialmente em 2004, quando o Ministério aprovou as Diretrizes Curriculares Nacionais do curso de Graduação em Design, através da Resolução CNE/CES no. 5, de 8 de março de 2004, com base nos pareceres CNE/CES no. 67 e no. 195/2003 de 5 de agosto de 2003. Dois anos mais tarde, em 2006, os catálogos dos cursos superiores de tecnologia foram publicados. A partir destas publicações, os bacharelados em moda, que até então possuíam uma infinidade de nomenclaturas distintas, passaram à área do design, enquanto os tecnológicos utilizaram o termo design de moda.

Independentemente da aceitação das escolas a este enquadramento, e das devidas adaptações curriculares, que não se restringiam à mera mudança de nomenclatura, o MEC passou a considerá-los cursos de design e, portanto, a submetê-los a provas de design no Exame Nacional de Desempenho (ENADE), nos anos subseqüentes.

A partir de então, as faculdades e universidades foram se encaminhando para assumir as propostas que melhor lhes convinham, estabelecendo o novo panorama do ensino superior de moda do país. Em 2008, os cursos de Design de Moda no Brasil alcançavam o número de 112 graduações e 24 especializações e Master Business Administration (MBA). Das graduações, 55 eram bacharelados, 42 tecnológicos e 15 sequenciais (PIRES, 2008). Passados três anos, em 2011, de acordo com dados publicados no site do E-mec ${ }^{2}$, as formações superiores em moda alcançaram o número de 174, representando, portanto, um significativo crescimento de 55\%. Destes, 75 bacharelados, 2 licenciaturas, 92 tecnológicos, 5 sequenciais. $\mathrm{O}$ surgimento das licenciaturas sinaliza uma preocupação positiva, mas ainda muito tímida, em formar profissionais para atuar neste cenário de expansão da formação em moda.

Em fevereiro de 2014, ao buscar os cursos de moda credenciados pelo MEC, percebe-se uma estagnação neste quantitativo, pois são registrados 175 cursos, apenas um a mais que os identificados em 2011. Contudo, mantém-se a tendência de preferência aos cursos tecnológicos, representando um crescimento de 15,2\%, ao mesmo tempo em que decresce o número de bacharelados em Moda em 13,3\%, conforme gráfico abaixo.

\footnotetext{
${ }^{2}$ Ministério da Educação. Disponível em <www.emec.mec.gov.br>. Acesso em 21 fev.2011.
} 


\section{Gráfico 1 - Modalidades de graduações em Moda no Brasil}

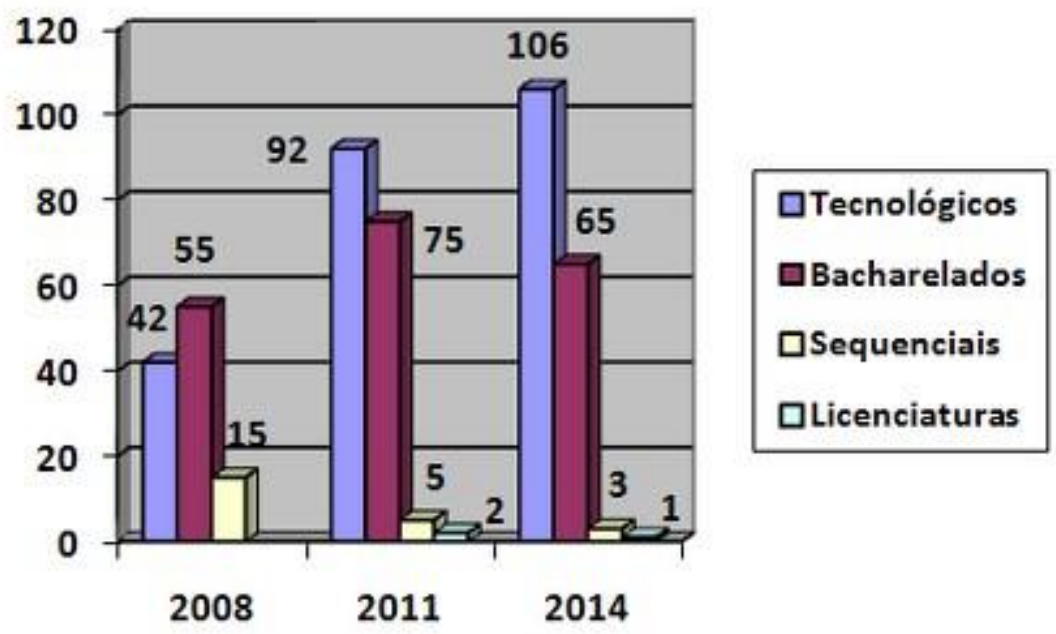

Fonte: QUEIROZ, 2014: p.98

Para Queiroz (2014), há, claramente, uma nova tendência formativa, que elege os cursos tecnológicos como modalidade:

Esta inversão da predominância dos cursos tecnológicos, a partir de 2011, em detrimento dos bacharelados, pode ser compreendida como uma resposta a um suposto aumento da demanda do mercado por este profissional mais tecnicista, mas, em alguns casos, como uma fuga aos exames do Exame Nacional de Desempenho que, desde 2006, trazem questões predominantemente do campo do Design. (QUEIROZ, 2014: 98)

De acordo com a autora, há muitos discursos e produções documentais de resistência à migração da moda ao design que apresentam preocupação com os resultados obtidos no ENADE, já que ele se apresenta com um foco mais generalista, sem se deter às questões próprias da moda/vestuário. Orientação esta que coaduna com a visão inter e multidisciplinar que parece ter influenciado o processo de enquadramento da moda ao design pelo MEC.

Os cursos tecnológicos, em contrapartida, são submetidos a provas com questões específicas de produtos têxteis e de vestuário. Para Queiroz (2014), “como apenas oito bacharelados em Moda são ofertados por instituições públicas, é possível que algumas IES, pressionadas por melhores resultados por seus mantenedores, possam ter optado por migrar para uma formação tecnológica" (p.98/99).

Sabemos que não se mede a força de um curso de graduação através de um único exame, inclusive o próprio Ministério leva em consideração diversos indicadores para a atribuição de conceitos. Soma-se a esta constatação, o fato dos resultados do ENADE 
virem, em alguns casos, mascarados por omissões estudantis. Entretanto, ao analisarmos os 76 cursos aos quais está atribuída uma nota referente ao ENADE 2012, percebe-se que os bacharelados têm obtido os piores resultados.

\section{Gráfico 2 - Notas dos cursos de Moda no ENADE 2012}

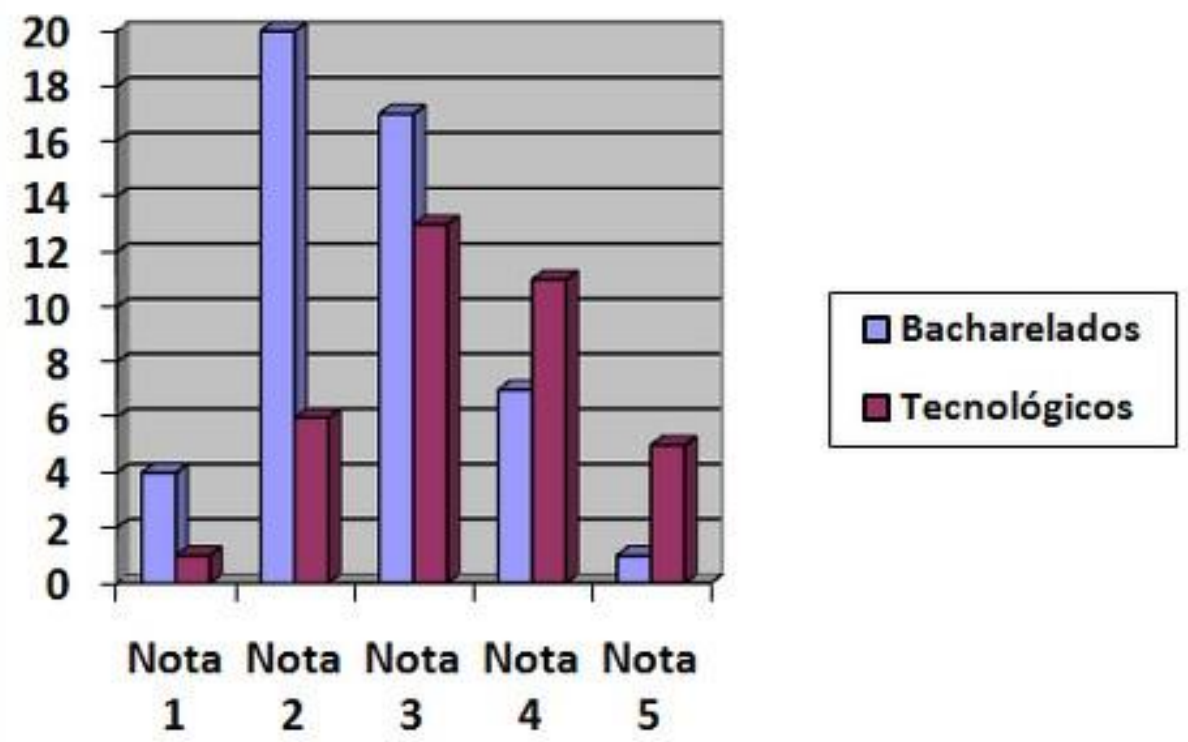

Fonte: QUEIROZ, 2014: p.99

Sobre a aceitação ao enquadramento, Queiroz (2014) verificou que dos 175 cursos, 137 apresentam o termo design em suas nomenclaturas, enquanto 38 optam pela nomenclatura moda, rejeitando a migração para o novo campo. O termo "estilismo", que até então vinha sendo utilizado para denominar os cursos e o profissional da área está em processo de extinção, sendo mantido apenas em dois deles ${ }^{3}$.

Curiosamente, os dois cursos que mantém o termo estilismo em suas nomenclaturas, o associa ao termo design, o que resulta numa combinação teoricamente inconsistente, já que são concepções diferentes sobre a construção do objeto do vestuário, e que legitimam e consagram diferentes produtores do campo: o estilista e o designer.

\footnotetext{
${ }^{3}$ SENACSP - Design de Moda - Estilismo; UFPI - Moda, Design e Estilismo.
} 


\section{Gráfico 3 - Nomenclatura dos cursos de Moda do Brasil}

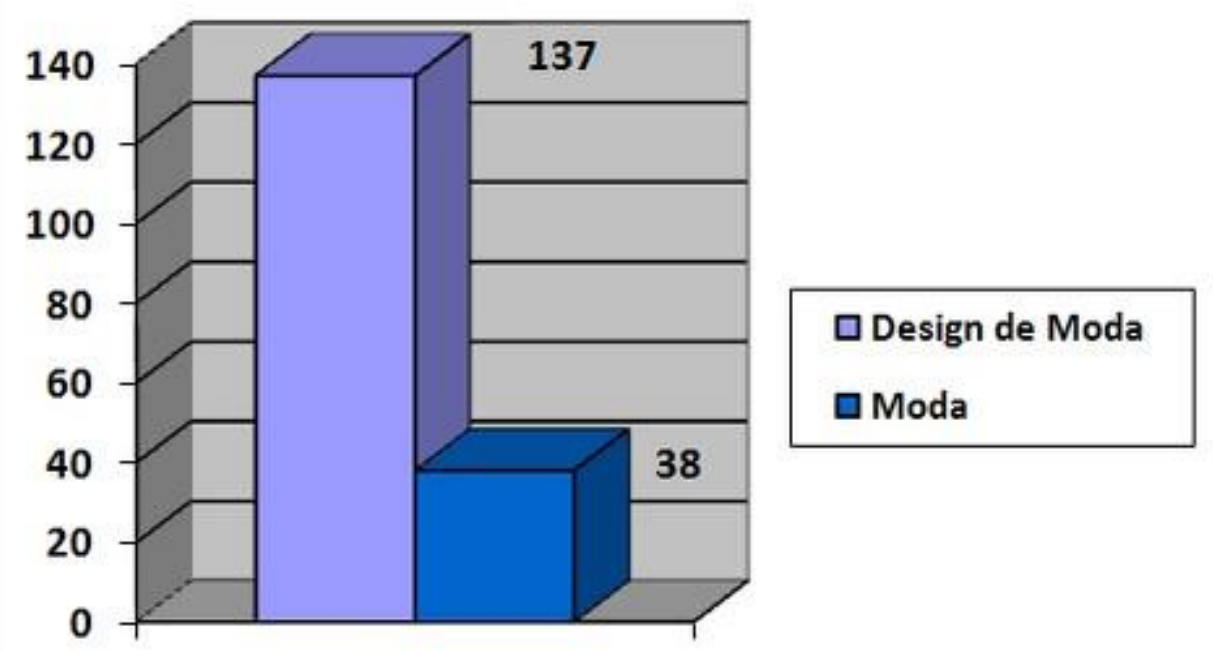

Fonte: QUEIROZ, 2014: p.101

Este processo de enquadramento da moda à área do design exigiu adequação dos currículos em um processo que pareceu arbitrário, mas que representou a visão e formação daqueles que detinham o poder junto ao Ministério. Em entrevistas realizadas com professoras que participaram deste processo, Queiroz (2014) verificou que a maioria conduziu as suas ações na crença de que havia muitas semelhanças entre a atuação do estilista e a do designer:

Foi criada uma comissão de quatro professores especialistas e que atuavam em cursos de Moda para pensar padrões de qualidade em Moda, e eu estava nesta equipe. Percebeu-se que, no mercado de trabalho, não se sabia como equivaler alguém que é formado em decoração ou em Estilismo. Então o procedimento foi o seguinte, em cada item, nós fomos nos perguntando se daria para colocar decoração, daria para colocar Moda? E aí a gente foi montando todos os itens de Design daquelas dimensões básicas e se chegou à conclusão de que não estávamos muito longe não, de que, de fato, aquelas práticas projetuais existiam na Moda, elas não eram nomeadas e nem reconhecidas (Trecho da entrevista de Carmélia Branca, em 2012, extraído da tese de QUEIROZ: 2014, p. 103).

Apesar da verificação de um processo responsável, conduzido por professores que faziam parte da história de formação em moda e design no país, esta comissão não foi eleita por seus pares e, portanto, estes não se sentiram por ela representados. "Parece não ter havido, à época, uma discussão coletiva consistente, em cujos fóruns se fortaleceria o posicionamento (...). Houve algum tipo de discussão nas escolas, que 
apresentam realidades e interesses particulares, mas o debate ficou apequenado e a sensação de ter ficado “de fora” do processo perdura até hoje.” (QUEIROZ: 2014, 104).

Além deste aspecto, o Ministério ofereceu pouco tempo para que as instituições adaptassem as suas realidades ao novo enquadramento, já que em 2004 lançou a portaria e, dois anos depois, já submeteu os bacharelados ao ENADE, que trazia questões que pressupunham uma formação em design.

Não se tratava apenas de um preparo documental, de ajuste das estruturas curriculares, mas, sobretudo, de um olhar atento aos docentes vinculados aos cursos, pois a maioria não apresentava aproximações com o novo campo:

\begin{abstract}
As pessoas estão apresentando uma fala que, na verdade, traduzindo, ela descobriu o Design. Ela pensa que está trazendo uma novidade, mas ela não sabe que o que está trazendo são os princípios básicos do Design, apresentados nas primeiras aulas de Design. Teria que trocar o corpo docente, ou trabalhar profundamente, ou capacitar. Eu tenho professores que são concursados, mas não são designers. Quem está ensinando a eles o que é Design? Isso está pegando nas orientações de TCC. Eu acredito muito nos coletivos. [...] Nós, educadores, não acordamos designers. As colegas falam de Design, e eu fico quieta. Desconhecem a história e acham que o Design é para todos, mas ele tem uma história de 50 anos (Trecho da entrevista de Acácia, em 2012, extraído da tese de QUEIROZ: 2014, p. 104)
\end{abstract}

Percebeu-se que, mesmo em defesa da migração, afirmando que o vestuário é um produto de design, e que, portanto, não há necessidade de criação das diretrizes para a moda, as entrevistadas reconhecem as dificuldades internas de aceitação, sobretudo relacionadas ao corpo docente, cuja formação não é em design. Tais questões necessitariam ser refletidas antes do enquadramento, para que não resultassem no engessamento das instituições públicas, ou nas demissões, muitas vezes injustas, nas instituições privadas.

Então, na verdade, quando o nosso curso começou, ele tinha esse lance do Estilismo muito forte [...]. Quando nós tivemos que mudar o enfoque foi um 'Deus nos acuda', porque ele não conseguia entender. [...]. O professor que era estilista, muitos deles a gente teve que fazer com que ele deixasse de trabalhar, porque o estilista profissional era aquele que há muitos anos trabalhava na indústria. Então ele quer é a visão do estilista, que é a visão do desenhista de Moda. Estes eram muitos dos melhores e mais antigos que nós tínhamos. [...] Então alguma mão de obra muito especial também foi perdida [...] (Trecho da entrevista de Gardênia, em 2012, extraído da tese de Queiroz: 2014, p. 104, grifo nosso.

O enquadramento dos cursos de moda ao design, portanto, vem sendo um processo complexo na história de formação no campo, que abre um espaço potencial 
para o debate em pelo menos quatro dimensões: a discussão sobre o poder dos bens simbólicos, e as disputas entre os agentes do campo da moda (estilistas e designers), porque justifica esta relação entre dominantes/dominados no processo de enquadramento; as relações existentes entre os significados desta passagem e a crise do paradigma científico, favorecendo, portanto, o processo da forma como se deu; as relações de poder que estão por trás dos discursos e das práticas de resistência; e os principais desafios formativos da mudança, tendo em vista que a alteração curricular extrapola a alteração de nomenclatura e passa a exigir docentes com formação em design. Nossa abordagem recai sobre este aspecto, particularmente a alteração curricular, no que tange ao modo como se passa a conceber produtos do vestuário na perspectiva do design.

\section{O Desenvolvimento de coleções na concepção formativa do Design}

O campo da moda se constituiu, nos últimos anos, a partir da presença do estilista como agente de dominação, sendo ele o profissional responsável pela criação autoral para a alta-costura; o produtor que se vincula às marcas e desenvolve produtos assinados em larga escala; aquele que projeta peças do vestuário em grandes quantidades, estas consideradas populares e de menor valor. Entretanto, este ofício que funda a noção do estilismo vai perdendo importância, na medida em que as instâncias formativas deixam de legitimá-lo e passam a capacitar outro produtor do campo, o designer. O principal desafio desta mudança consiste na compreensão do seu significado e da correta adequação das estruturas curriculares, de modo a se evitar a formação de egressos em design, sem que apresentem tais competências e habilidades.

Christo e Cipiniuk (2013) defendem que as funções desempenhadas por designers de moda ou estilistas são semelhantes, já que ambos precisam dominar a forma e os processos criativos, conhecer os usuários dos seus produtos, os materiais e processos de fabrico dos mesmos, e os fatores que afetam os custos produtivos.

[...] parece facilmente aceitável o argumento de que o processo de criação, desenvolvimento, produção e distribuição dos objetos do vestuário e de qualquer outro objeto pertencente ao campo do Design são semelhantes e de que as características formais de um objeto de Design e de um objeto do vestuário vinculado à Moda não são isentos e imparciais em relação às questões estéticas e estilísticas vinculadas a determinados períodos de tempo que determinam a sua obsolescência (CHRISTO, 2013, p. 65). 
As semelhanças também podem ser verificadas na prática de estilistas e designers, pois para uma atuação competente, ambos precisam conhecer a forma e os usos dos objetos que criam. É necessário que dominem os processos criativos, os materiais, modos de fabricação, produção e distribuição. Além disso, acompanham todo o processo e os custos demandados, para avaliar a viabilidade produtiva, considerando o público-alvo para o qual o objeto se destina.

Mesmo assim, sabemos que há um movimento natural da estrutura dos campos, na qual os seus agentes ou instituições medem forças e resistem um ao outro. (BOURDIEU, 1983). Verificamos que, nas duas formas de resistir, há um desmerecimento do designer ao olhar do estilista, e vice versa, conforme atestam Christo e Cipiniuk (2013):

\begin{abstract}
De forma semelhante, tanto alguns designers parecem ter dificuldade de perceber o vínculo da sua atividade com noções normalmente atribuídas ao fenômeno Moda, como a valorização da autoria, a relação entre o produtor e a constituição do valor simbólico do objeto desenvolvido, a valorização da noção de novo, o estabelecimento de um estilo possível de ser identificado como expressão formal de determinado produtor; como os produtores de objetos do vestuário parecem ter dificuldade em perceber as relações da sua atividade com noções normalmente associadas ao Design, como a relação com os requisitos impostos pelas demandas do mercado e o desenvolvimento de objetos direcionados aos usuários e não aos criadores, mesmo para objetos de vestuário aparentemente autorais, livres e autônomos (CHRISTO; CIPINIUK, 2013, p. 2-3).
\end{abstract}

Um dos argumentos que comumente encontramos entre os que defendem a manutenção da moda como área no MEC, é o de que o trabalho do estilista é criativo, inovador e livre, o aproxima do conceito de artista, de genialidade, conferindo-lhe o papel mais importante do epicentro da moda. Assim, o produto que gera segue a lógica de uma expressão individual e autônoma, que apresenta dificuldades para ser mensurado, controlado ou previsto. Por outro lado, o designer pode ser comparado a um técnico racional e lógico, que se compromete com as demandas do mercado e dos produtores sem autonomia para criar e inovar. Contudo, ele gera objetos planejados, cujos resultados podem ser previstos, o que o configura como detentor de uma qualidade superior, pelo bom desempenho do seu produto, dotado de grande valor simbólico. "[...] esta noção [...] acaba aproximando o designer da mesma noção de gênio criador vinculada ao campo da arte que o diferencia e afasta de outros produtores não legitimados como designers pelo campo [...]" (CHRISTO, 2013, p. 70). Neste sentido, o 
que muda entre os dois campos é que esta qualidade poderia ser adquirida pela formação, enquanto o estilista é um artista de essência, nasceu com esta capacidade artístico-criativa que o distingue.

No Brasil, segundo Christo (in: PIRES, 2008), o design foi aproximado da ciência e da técnica e afastado do campo da arte, o que reforçou a desvalorização do designer, por afastá-lo da noção de criador autoral e autônomo. Por outro lado, o discurso da sua necessidade se configurar como uma área tecnicista se justifica por sua tradição modernista. Esta oposição entre o profissional livre e autônomo e o que está preso aos ditames do mercado vem a se tornar o objeto de disputa necessário para o funcionamento do novo campo.

Para Queiroz (2014), a mesma capacidade que qualifica o designer, pela sua competência projetual, pois lhe assegura uma condição única no campo, igualmente o diminui, pois o projeta como um profissional limitado e preso às demandas do mercado. Portanto, posicionar-se em meio a esta e a outras ambiguidades do novo campo, vai depender das diferentes posições e relações de poder dos seus agentes.

Estamos cientes de que não há como defendermos uma produção autônoma e completamente desvinculada dos valores do mercado, assim como também não defendemos que se produza apenas para ele. O designer não desenvolve exclusivamente para atender às demandas do mercado, do 'grande público', pois em alguns casos ele pode se dedicar à produção de objetos direcionados ao seu próprio campo, segundo critérios do mesmo.

De igual modo, o estilista, que assume a posição de livre e detentor de um talento individual único, com a sua assinatura de alto valor econômico e simbólico, ao mesmo tempo pode se vincular à indústria do mercado, distanciando-se de sua autoralidade.

No intuito de estabelecer distinções, portanto, defendemos que há um exagero nas estratégias de ambos os produtores, estilistas e designers. Neste sentido, há uma supervalorização da capacidade projetual deste, no intuito de legitimar a sua posição como pretendente a dominante no campo. Os estilistas, por sua vez, recusam o exagero e, de igual forma, potencializam a sua capacidade autoral e livre. (CHRISTO, 2013). Assim, somente a compreensão da metodologia projetual, e dos percursos metodológicos utilizados por estilistas e designers nos ajuda a melhor compreender a 
forma como esta vem sendo potencializada na polarização entre os dois agentes do campo.

\section{A Moda e a Metodologia de Design}

Para Löbach (2001, p.16), "[...] o conceito de design compreende a concretização de uma ideia em forma de projetos ou modelos, mediante a construção e configuração resultando em um produto industrial passível de produção em série". Tal produto é resultado de um processo de pesquisa e desenvolvimento, que visa atender a uma determinada necessidade de um determinado público, sem deixar de atender aos interesses da empresa. Atualmente essas relações se tornam cada vez mais complexas, e novas variantes vão sendo inseridas nesse contexto, como por exemplo, a atenção às questões ambientais.

Entendemos que pensar a moda, além das relações sociais, é também pensar o produto. Situá-la dentro do campo do design, pensando a partir do ponto de vista da indústria e do produto, implica em utilizar metodologias, ou processos, específicos para o desenvolvimento de produtos e serviços. Assim, faz-se necessário compreender o que vem a ser uma metodologia projetual e de que forma ela pode ser aplicada ao desenvolvimento de produtos de moda.

De acordo com Bürdeck (2006), teve início nos países europeus, após a Segunda Guerra, um processo de grande crescimento econômico, e por consequência, de concorrência internacional, os quais o autor classifica como parte do processo de globalização. Por conta dessas novas condições econômicas e industriais, o design precisou abandonar a subjetividade das manufaturas e se adaptar à racionalização da indústria, tanto no projeto, na construção, como na produção dos bens. Isso fez com que os métodos científicos fossem incorporados aos processos de projeto, e o design fosse aceito como parceiro da indústria.

De acordo com o autor, a metodologia projetual de design tem início nos anos de 1960, através da Escola de Ulm. Pelo caráter cientificista da escola, diversos métodos foram investigados e experimentados quanto à sua aplicabilidade para o desenvolvimento de produtos. A partir das pesquisas empreendidas, as metodologias que surgiram se fundamentaram, com sutis variações, a partir de alguns princípios e diretrizes que geralmente encaminhavam o processo de uma forma linear: compreender 
e definir o problema, coletar informações, analisar as informações coletadas, desenvolver conceitos de produto, avaliar as alternativas, escolher a solução, testar e implementar.

Segundo Bürdeck (2006), já na década de 1960 alguns pesquisadores se questionavam a respeito da linearidade de uma metodologia, tendo em vista que "[...] tarefas diferentes necessitam de métodos diferentes e a pergunta crucial a ser colocada no início do processo de design é a de qual método deve ser empregado em qual problema" (BÜRDECK, 2006, p. 251). Isso fez surgirem inúmeras metodologias, também conhecidas como processos de design, que apresentavam maiores ou menores diferenças entre si. Contudo, apesar de cada autor apresentar a sua metodologia de forma distinta, a base sempre foi a mesma. O que variou, em muitos casos, foi a abordagem metodológica, ou seja, que tipo de abordagem foi dada para o desenvolvimento de cada tipo de produto, ou que considerações deveriam ser levadas em conta para cada caso.

As metodologias se apresentam como ferramentas úteis aos profissionais de design, facilitando os processos e a tomada de decisões. Entender o fluxo do projeto de um produto amplia a capacidade de se projetar. Conhecer as necessidades e especificidades projetuais de cada tipo de produto/serviço e aplicá-las ao tempo certo é fundamental para gerar bons designs.

\footnotetext{
A Metodologia de Design poderia ser entendida então como um processo esquematizado e apoiado em etapas distintas, com o objetivo de aperfeiçoar e auxiliar o Designer (ou a equipe de Design) no desenvolvimento ou concepção de soluções para um determinado problema através de um artefato (seja um produto ou um serviço), oferecendo um suporte de métodos, técnicas ou ferramentas. (VASCONCELOS et al, 2015, p. 3)
}

O campo do design apresenta atualmente um número crescente de novas metodologias projetuais. Muitas delas altamente específicas que atendem a um determinado tipo de problema, enquanto outras se propõem a apresentar fluxos genéricos que servem tanto para produtos quanto para serviços. Temos também algumas metodologias que se apresentam mais como abordagens metodológicas, como é o caso do Metaprojeto.

Para analisarmos o método de Treptow à luz da metodologia projetual de Löbach e do Metaprojeto de Moraes, apresentaremos, inicialmente, as etapas da metodologia de Löbach relacionando-as às etapas da metodologia de Treptow, 
apontando suas semelhanças. Em seguida, discutiremos as relações entre as pesquisas apresentadas por Treptow e o Metaprojeto, apontando possibilidades para a utilização do conceito de cenários na metodologia de moda.

No livro 'Inventando Moda: Planejamento de Coleção', Treptow (2013) apresenta o que consideramos a primeira metodologia para o desenvolvimento de coleções conhecida no Brasil. Segundo a autora, a publicação surge de um material didático desenvolvido para as aulas da disciplina de Planejamento de Coleção, e a primeira edição é publicada em 2003. Além de discutir algumas questões estratégicas relacionadas à marca de moda, à gestão do design e à pesquisa, a autora apresenta um esquema com as etapas do processo de desenvolvimento de coleções que são vivenciadas na indústria.

A moda apresenta um ciclo bastante breve, e o desenvolvimento de produtos precisa atender a uma demanda crescente por novidades. As coleções tem curta duração nas fábricas e lojas, e algumas vezes os designers trabalham em mais de uma coleção ao mesmo tempo. Esta característica produtivo/comercial é muito marcante na moda: sua efemeridade. Por isso, os tempos necessários aos processos são mais curtos do que na maioria dos produtos de design, e em geral se obedece a uma lógica sequencial nas coleções. É um processo que, na maioria das vezes, não envolve inovações. É rotineiro e apresenta um fluxo constante, com datas definidas a partir de um calendário estabelecido nacionalmente.

Assim, os processos de design de moda são bastante específicos, pois precisam atender a demandas bem definidas. Devem corresponder às expectativas de produção e comercialização da indústria, além de atender a um processo de obsolescência bastante rápido. Isso exige que as metodologias sejam adaptadas, ou que sejam estruturadas metodologias específicas para os produtos de moda.

De acordo com Löbach (2001, p.141), "todo o processo de design é tanto um processo criativo como um processo de solução de problemas". Para o autor, uma sequência lógica na solução do problema pode ser organizada em 4 etapas maiores, que podem se desdobrar em outras menores, além de se interrelacionar umas com as outras através de avanços e retrocessos. Cada uma dessas etapas pode ser relacionada com as etapas do método de Treptow, conforme veremos a seguir.

A primeira etapa apontada por Löbach (2001, p.142) consiste na definição e análise do problema, denominada por ele de "Fase de Preparação", ou Análise do 
Problema. Neste momento se desenvolvem as pesquisas, coletam-se e analisam-se informações sobre o problema (ou produto), estabelecem-se as relações do produto com o usuário, analisa-se o mercado, etc. Para o autor, as informações a serem coletadas dependem da abrangência e da importância do problema. É a solução dele que vai determinar que tipos de informações e que nível de detalhamento são necessários ao projeto. Assim, não se pode estabelecer com precisão que tipos de pesquisas e análises serão necessárias em cada caso, tudo vai depender do tipo de produto que se pretende desenvolver.

No método de Treptow (2013), essa primeira fase se constitui em um processo de Planejamento. Antes de iniciar o processo de desenvolvimento de uma coleção, fazse necessário considerar o perfil da marca e o perfil do consumidor. Toda coleção deve trazer consigo a identidade da marca e deve atender ao seu público consumidor. A junção desses dois perfis será personificada através do tema de coleção, das formas e das matérias-primas utilizadas.

As informações de perfis são levadas a uma reunião de planejamento, em que são definidos o cronograma, os parâmetros e dimensão da coleção, as estratégias de produção, lançamento e comercialização. Neste momento pode ser definido um norte para a pesquisa de tendências, bem como o tema ou motivo de inspiração para a coleção que será desenvolvida. Tudo isso será compilado em um briefing, que conduzirá a equipe de criação. Este documento deverá conter ainda tudo o que é necessário para o trabalho da equipe, incluindo limitações financeiras, de materiais, de prazos, etc.

A próxima etapa para Treptow, que ainda encaixamos dentro da primeira fase de Löbach, são as Pesquisas, que serão compiladas em formato de painéis imagéticos. Para a autora, "a pesquisa deve ser uma constante no dia a dia do designer de moda" (TREPTOW, 2013, p.71). Ela deve se tornar um acompanhamento constante do mercado, do consumidor, das tecnologias e tendências.

Assim, serão elaboradas as pesquisas e análises de comportamento, de mercado, tecnológica, de vocações regionais, de tendências e de tema de coleção. A partir dos painéis, em especial do painel de tema de coleção e do de tendências, são extraídas as cores que irão compor a cartela da coleção, levando sempre em consideração a oferta de tecidos e aviamentos dos fornecedores. Além disso, nesta etapa se definem também as matérias-primas. Defini-las antes de iniciar o processo de desenho é fundamental, pois 
as texturas e caimentos serão de extrema importância no desdobramento das formas e silhuetas.

A segunda fase da metodologia de Löbach (2001, p.142) consiste na "Fase da Geração", ou Geração de Alternativas. Segundo o autor, "gerar ideias é a produção das diversas alternativas possíveis para solucionar o problema em questão" (p. 153). Neste momento se estudam as possibilidades formais dos novos produtos, suas configurações, através de métodos criativos, esboços, desenhos, modelos e experimentações.

Em Treptow (2013), esta fase é denominada Design. Podemos apontar o início dela com o estudo e definição dos elementos de estilo e de design, que são extraídos dos painéis a partir de rascunhos e esboços. Tais elementos agregarão identidade e coerência às peças da coleção, e ajudarão a reforçar a referência ao tema escolhido. Ao mesmo tempo, inicia-se o processo de desenvolvimento dos modelos através de desenhos e croquis. Segundo a autora (IDEM, 2013, p. 137), "[...] o croqui é uma ferramenta importante, pois através dele (na postura dos manequins, no uso de acessórios, nas combinações produzidas) é que o designer transmite a relação entre as peças isoladas e o tema de coleção".

Em geral, são utilizadas técnicas criativas para a geração do maior número possível de modelos, que na próxima fase serão selecionados para compor a coleção. Treptow (2013) defende que devem ser esboçadas ao menos três propostas de produto para cada peça definida no parâmetro de coleção. Aqui também podem ser realizados testes de caimento de tecidos, de detalhamentos de modelagem, bem como se pode recorrer à moulage para se estudar formas, silhuetas e caimentos diretamente no manequim. Tudo vai depender do processo adotado pela empresa.

$\mathrm{Na}$ terceira fase da metodologia de Löbach (2001, p.142) temos a "Fase de Avaliação", ou Avaliação das Alternativas. Nela são analisadas e comparadas as opções de produtos geradas anteriormente, sua viabilidade produtiva e comercial, e se procede ao processo de seleção do melhor produto. Neste momento podem ser sugeridas alterações e/ou adaptações às ideias geradas, a fim de se obter um produto mais adequado às expectativas.

Com os modelos em mãos, segundo Treptow (2013), realiza-se uma reunião para a definição da coleção, que "[...] tem por objetivo avaliar a proposta de coleção, sugerindo alterações que possam facilitar a produção, reduzir custos ou tornar o produto mais atraente ao consumidor" (IDEM, 2013, p.149). Nela é feita uma triagem da 
coleção em que são selecionados os modelos que irão compor a coleção, e são descartados os modelos excedentes. São levados em conta os perfis da marca e do consumidor, o tema de coleção, as tendências, além da viabilidade produtiva e comercial das peças. Nesta fase, busca-se organizar os modelos em famílias, nas quais são priorizadas a coerência e combinação das peças entre si.

Para Löbach (2001, p. 142), a quarta e última fase do processo de design é a "Fase de Realização", ou Realização da Solução do Problema, em que se materializa a alternativa escolhida. Neste momento a alternativa ainda pode ser retocada ou aperfeiçoada, transformando-se em um projeto detalhado e em um protótipo. O projeto deve conter todos os desenhos e especificações necessárias à produção, a fim de garantir que o produto será realizado com a maior precisão de detalhes possível.

O equivalente a essa fase, no método de Treptow (2013), é a fase do Desenvolvimento. Aqui são produzidas as fichas técnicas, com os desenhos técnicos detalhados e todas as especificações necessárias. São desenvolvidas as modelagens, com suas graduações. É feita a prototipagem de cada produto, e são realizados todos os testes necessários para garantir que a peça sairá como o planejado. Além disso, nesta etapa são calculados os custos e os preços finais de cada peça.

Segundo a autora, a coleção ainda passa por uma última reunião de aprovação, em que são apresentados os protótipos a toda a equipe da empresa, incluindo o pessoal do marketing e das vendas. Caso haja alguma alteração, ou mesmo rejeição, os produtos retornam à segunda etapa, e uma nova reunião de avaliação pode ser organizada.

A seguir, um quadro comparativo das metodologias: 
Tabela 1 - Quadro comparativo das metodologias

\begin{tabular}{|c|c|c|}
\hline & Metodologia de Löbach (2001) & Metodologia de Treptow (2013) \\
\hline \multirow{15}{*}{ Fas e 1} & \multirow{15}{*}{$\begin{array}{c}\text { Fase de Preparação ou } \\
\text { Análise do Problema }\end{array}$} & \begin{tabular}{|l|} 
Fase de planejamento \\
\end{tabular} \\
\hline & & - Reunião de Planejamento \\
\hline & & $\begin{array}{l}\text { - Definição de perfil da marca e do } \\
\text { consumidor }\end{array}$ \\
\hline & & - Definição do cronograma \\
\hline & & $\begin{array}{l}\text { - Definição dos parâmetros e } \\
\text { dimensão da coleção }\end{array}$ \\
\hline & & $\begin{array}{l}\text { - Estratégias de produção e } \\
\text { comercialização }\end{array}$ \\
\hline & & - Definição do tema de coleção \\
\hline & & - Diretrizes para a pesquisa de \\
\hline & & \begin{tabular}{|c|} 
Fase de Pesquisas \\
\end{tabular} \\
\hline & & - Pesquisa de comportamento \\
\hline & & - Pesquisa de mercado \\
\hline & & - Pesquisa tecnológica \\
\hline & & - Pesquisa de vocações regionais \\
\hline & & - Pesquisa de tendências \\
\hline & & - Pesquisa de tema de coleção \\
\hline \multirow{6}{*}{ Fase 2} & \multirow{6}{*}{$\begin{array}{c}\text { Fase da Geração ou } \\
\text { Geração de Alternativas }\end{array}$} & \begin{tabular}{|c|} 
Fase do Design \\
\end{tabular} \\
\hline & & $\begin{array}{l}\text { - Definição de elementos de estilo e } \\
\text { de elementos de design }\end{array}$ \\
\hline & & - Geração de alternativas \\
\hline & & - Esboços, desenhos,croquis \\
\hline & & - Desenhos de estampas \\
\hline & & - Experimentações, testes, moulage \\
\hline Fase 3 & $\begin{array}{c}\text { Fase da Avaliação ou } \\
\text { Avaliação das Alternativas }\end{array}$ & - Reunião de Definição \\
\hline \multirow{6}{*}{ Fase 4} & \multirow{6}{*}{$\begin{array}{c}\text { Fase da Realização ou } \\
\text { Realização da Solução do } \\
\text { Problema }\end{array}$} & \begin{tabular}{|c|} 
Fase do Des envolvimento \\
\end{tabular} \\
\hline & & - Desenvolvimento de fichas técnicas \\
\hline & & - Desenvolvimento de modelagens \\
\hline & & - Graduação dos moldes \\
\hline & & - Prototipagem \\
\hline & & - Reunião de aprovação \\
\hline
\end{tabular}

Fonte: das autoras

Apesar da linearidade, o processo de desenvolvimento de coleções de moda pode sofrer retrocessos, a fim de se executar correções ou melhorias nos produtos. Em todas as fases podem ser estabelecidas avaliações, ou feedbacks (VASCONCELOS et al, 2010) para garantir que as diretrizes de projeto pré-estabelecidas estão sendo cumpridas satisfatoriamente, ou mesmo para se rever as diretrizes iniciais. Na moda não há tanta flexibilidade como em alguns processos de desenvolvimento de outros tipos de produtos industriais, pois aqui o tempo do processo é reduzido. Assim, não é comum existirem retornos para etapas anteriores, mas eles podem existir quando necessário. 
Após revisarmos o processo proposto por Treptow, frente à metodologia de design de Löbach, consideramos estar adequado às exigências da indústria de produtos de moda, em especial de vestuário, ao mesmo tempo em que se configura como uma metodologia válida, que acompanha as diretrizes gerais das metodologias de design.

Pode-se perceber, então, que uma coleção de moda é o resultado do processo de desenvolvimento de produtos - roupas ou acessórios - seguindo um planejamento prédefinido através de uma metodologia, em que são cumpridas diversas etapas com o objetivo de garantir a unidade visual dos produtos e sua viabilidade produtiva e comercial. A coleção, ou resultado final do processo, responde visualmente e conceitualmente aos perfis da marca e do consumidor, carregando elementos formais e estéticos inspirados em um determinado tema, que por sua vez sintetiza diversas possibilidades de criação.

\section{A Importância da Pesquisa na Metodologia Projetual de Moda}

Muito se tem discutido sobre o design e a sua atuação no mundo complexo e dinâmico em que vivemos. Um dos pontos dessa discussão tem sido a linearidade e previsibilidade das metodologias tradicionais. Assim, a fim de propor uma atualização da metodologia de moda, analisamos a fase de pesquisa proposta por Treptow, relacionando-a ao Metaprojeto, e apontando possibilidades de interdisciplinaridade.

De acordo com Moraes (2010), o Metaprojeto atua principalmente nas fases iniciais do projeto, ou da metodologia. Seja através da observação da realidade existente, seja através da prospecção de cenários futuros. Segundo o autor, o metaprojeto é um modelo projetual que se estrutura na fase anterior ao projeto, a fase da pesquisa, na qual se desenvolve a reflexão a respeito do produto que será desenvolvido.

Sua estruturação se dá a partir da noção de cenários (atuais ou futuros), e se organiza através dos pack of tools, ou pacotes de conhecimentos, que serão diretrizes nos processos de pesquisa. Para Moraes:

O cenário vem entendido como o local em que ocorrem os fatos, o pano de fundo que ilustra uma ação teatral, o espaço para a representação de uma história constituída de vários elementos e atores, no seu desempenho narrativo.. O cenário também se determina como o panorama e paisagem em 
que se vive (cenário existente) ou se viverá (cenário futuro) [...]. (MORAES, 2010, p.3)

Até a década de 1990, a demanda era maior do que a oferta, caracterizando o chamado 'cenário estático'. A comercialização dos produtos era fácil, o comportamento do consumidor era linear, e a indústria ainda detinha o poder de decidir o que seria produzido. Com a capacidade produtiva sendo nivelada entre os países, a livre circulação de matérias-primas e produtos, e a disseminação de novas tecnologias, é estabelecido um novo cenário, agora marcado pela busca da decodificação dos atributos intangíveis e imateriais dos produtos. Neste cenário dinâmico, o design precisa se adaptar à transversalidade e subjetividade das disciplinas, à abundância de informações e à concorrência pelo interesse do consumidor. Aqui, a oferta é superior à procura, e o que vai encantar o usuário é uma combinação em perfeito equilíbrio de atributos tangíveis e intangíveis (MORAES, 2010, 2011). O cenário dinâmico é marcado pela fluidez, pelas incertezas, pela imprevisibilidade.

A metodologia, hoje, segundo o autor, precisa dar atenção à dinâmica que gira em torno do produto, à história dos objetos, pensados como uma interseção de várias histórias, e às marcas que os objetos deixam nos seus usuários. Desenvolver produtos é pensar holisticamente, a partir de um cenário em que diversas ciências se interconectam, dialogam, se relacionam.

\footnotetext{
"O metaprojeto vai além do projeto, pois transcende o ato projetual. Trata-se de uma reflexão crítica e reflexiva preliminar sobre o próprio projeto a partir de um pressuposto cenário em que se destacam os fatores produtivos, tecnológicos, mercadológicos, materiais, ambientais, socioculturais e estético-formais, tendo como base análises e reflexões anteriormente realizadas antes da fase de projeto, por meio de prévios e estratégicos recolhimentos de dados". (MORAES, 2010, p. 25)
}

O metaprojeto é organizado em uma estrutura disciplinar cujos tópicos norteiam sua aplicação. Segundo Moraes (2010), essa estrutura inicial pode ser expandida e ampliada para atender às necessidades projetuais da complexidade. Os tópicos podem ser utilizados aleatoriamente, não sendo exigida uma sequência específica, e juntos contribuem para a formação de uma cultura de projeto. São eles: fatores mercadológicos, sistema produto/design, sustentabilidade socioambiental, influências socioculturais, fatores tipológico-formais e ergonômicos e, por fim, tecnologia produtiva e materiais empregados. 
Para Treptow (2013), o processo de pesquisa para o desenvolvimento de coleções se dá através de 6 eixos: comportamento, mercado, tecnologia, vocações regionais, tendências e tema de coleção. Ela sugere que todas as pesquisas devem ser estruturadas em forma de painéis imagéticos, a fim de facilitar a visualização das ideias. Além disso, ela enfatiza a necessidade da definição dos perfis da marca e do consumidor, que se consolidam como pesquisas complementares. Sugerimos aqui que os perfis também sejam compilados de forma imagética em painéis.

Assim como o pacote de conhecimentos metaprojetuais, os eixos de pesquisa de moda não apresentam uma sequência predeterminada, e podem ser organizados de acordo com as necessidades de projeto. Podem apresentar informações interrelacionadas, dialogando entre si. Faremos a análise, portanto, seguindo a ordem apresentada por Treptow, precedida pelos perfis de marca e de consumidor.

Desenvolver um produto, ou uma coleção, para uma determinada empresa, exige que o designer conheça e respeite o perfil definido para aquela marca. Como perfil, podemos compreender a identidade, a missão e o posicionamento estratégico. Segundo Treptow (2013, p.53), "a marca é o identificador de um produto", mas vai também além disso: "[...] representa o significado que um produto possui para uma pessoa, e isso inclui o nome, a representação gráfica (logomarca) e as emoções associadas pelas pessoas aos produtos".

A fim de aprofundar a experiência do design relacionado à marca, pode ser feito um levantamento mais detalhado da marca aplicando a pesquisa de fatores mercadológicos, do metaprojeto. Através dele, podem ser identificadas a identidade, missão e posicionamento estratégico, bem como podem ser definidos o cenário em que a marca atua/atuará, sua visão e o concept de novos produtos. A utilização do metaprojeto nesta etapa da pesquisa vai ajudar a definir os atributos dos novos produtos e ampliar o entendimento do projeto (MORAES, 2010).

Para Moraes (2010, p. 40), é possível delimitar dois tipos de cenários: o existente e o futuro. "O cenário existente na verdade não é se não a fotografia da realidade momentânea", enquanto "o cenário futuro pode ser também percebido como antecedência (inovação) [...] um importante vetor de prospecção, de prefiguração do ambiente em que a empresa vai operar" (p. 41). A visão pode ser descrita como o delineamento de um cenário. Ela "[...] se articula sempre por meio da interação entre a pesquisa e as reais possibilidades de execução, isto é, as chances de que o produto 
venha ser produzido de forma competitiva dentro do mercado em que atuará" ( p.43). Como conceito, ou concept, pode-se entender uma possibilidade projetual que traz algumas informações sobre as possíveis configurações visuais do produto (p. 43).

O perfil do consumidor pode ser estabelecido paralelamente ao perfil da marca, a partir das pesquisas e definições apontadas acima, em especial através da segmentação de mercado. Devem-se levar em consideração as demandas cada vez mais distintas e as expectativas dos consumidores pelos atributos intangíveis e imateriais dos produtos. É importante notar que os perfis da marca e do consumidor precisam estar em sintonia, para garantir o sucesso das coleções, sendo imprescindível que haja uma identificação imediata entre os dois atores dessa relação, que se dará através do produto.

$\mathrm{O}$ primeiro eixo das pesquisas sugerido por Treptow diz respeito ao comportamento do consumidor, através da Pesquisa de Comportamento. Saímos do campo de definir quem é o consumidor, para estabelecer suas características de comportamento. Este eixo de pesquisa, segundo ela, "acompanha os hábitos de consumo do público-alvo e seus interesses atuais" (TREPTOW, 2013, p. 72).

Para avaliar o comportamento do consumidor, podemos nos utilizar do painel do consumidor elaborado anteriormente, associado às pesquisas dos fatores tipológicos, formais e ergonômicos do metaprojeto. Estes dizem respeito não apenas à relação entre homem/espaço/produto, mas também à dimensão emotiva envolvida nessa relação, através da constelação de valor. Segundo Moraes (2010, p. 100), a constelação de valor é "uma ação multidisciplinar na qual estão inseridas contribuições de várias disciplinas de aspectos e caracteres múltiplos. Valor é, então, aquilo que é relevante e, por isso mesmo, contempla as cargas afetivas, simbólicas, e de igual maneira, as culturais". Isso significa que compreender o comportamento do consumidor é ao mesmo tempo entender quais são os seus valores.

No segundo eixo de pesquisa de Treptow é feita uma Pesquisa Comparativa de Mercado, na qual se investigam "estilos e preços praticados pela concorrência, produtos paralelos direcionados ao mesmo público-alvo, novas marcas (futuros concorrentes)" (IDEM, 2013, p. 72). Neste momento devem ser levantados os concorrentes diretos e indiretos, bem como os produtos semelhantes que podem interferir nas vendas.

Se o cenário existente tiver sido bem elaborado no primeiro momento de definição de perfil da marca, ele poderá oferecer as informações necessárias ao painel de mercado. Assim, basta aprofundar a pesquisa dos concorrentes neste momento, 
levando em consideração as características da marca e do mercado no qual ela se propõe a atuar.

A Pesquisa Tecnológica apresenta-se como o terceiro eixo para Treptow. Ela "acompanha lançamentos de técnicas e maquinários que possam ser aplicados à confecção" (IDEM, 2013, p. 72). Além disso, esta pesquisa se debruça sobre novos materiais e tecnologias disponíveis para a indústria, novos sistemas produtivos, softwares, etc, que "acabam também por influenciar a concepção e a estética de novos produtos" (MORAES, 2010, p. 82). Em muitos casos, a pesquisa de matérias-primas para a coleção é feita neste momento.

No tópico metaprojetual da tecnologia produtiva e materiais empregados, Moraes discute a necessidade de se pesquisar novidades que possam despertar nas pessoas "[...] valores antes de difícil mensuração, como, por exemplo, a emotividade, a estima e a qualidade percebida" (IDEM, 2010, p. 83). Trazer para o vestuário uma matéria-prima que provoque novas sensações é, possivelmente, ampliar toda a constelação de valor do produto. Ele aponta ainda a necessidade de se pesquisar as características materiais e dimensionais dos produtos/matérias-primas, sua cadeia produtiva, bem como os processos produtivos aplicados aos produtos/matérias-primas.

A Pesquisa de Vocações Regionais baseia-se na ideia de que o produto pode ganhar vantagem competitiva através da diferenciação promovida pelo uso das vocações de cada região. Ela "visa a obter fontes para materiais e técnicas alternativas, conforme a disponibilidade de insumos ou mão de obra" (TREPTOW, 2013, p. 72). São investigadas as tradições artesanais de cada região, com suas heranças culturais. Além de auxiliar na preservação de traços culturais e na sustentabilidade de comunidades artesãs, o designer pode agregar um valor especial aos seus produtos ao aplicar produtos artesanais em suas criações.

No tópico 'fatores socioculturais' do metaprojeto, Moraes (2010, p. 70) defende que "a proposta de um novo produto, de forma consciente ou não, é fruto da interação dos atores envolvidos na concepção dos artefatos com a realidade sociocultural circundante". Ele completa ainda que "a identidade local, por meio de valorização do território (terroir), aponta-se como um modelo de diferenciação para os bens de produção industrial contemporânea" (p. 71). O autor ainda ressalta que a moda brasileira tem grande potencial de se destacar mundialmente ao apresentar seus traços culturais nas coleções, reforçando a identidade do seu design. 
O próximo eixo de pesquisa de Treptow é a Pesquisa de Tendências. Ela "identifica temas de inspiração de outros designers, informações sobre cores, tecidos, aviamentos, elementos de estilo" (TREPTOW, 2013, p. 72). Em geral essas informações são obtidas pelos designers em feiras e bureaux de estilo, que identificam e interpretam as tendências de comportamento, os desejos e ansiedades do mercado, monitorando suas reações a cores, design e produtos. Neste eixo pode-se utilizar o cenário futuro definido anteriormente, e que muitas vezes já é oferecido pelos bureaux de estilo. Ele pode fornecer informações importantes a respeito das tendências de mercado e comportamento.

\begin{abstract}
Ao realizar uma pesquisa sobre inspirações de moda, o designer pode usar vários materiais, como vídeos, fotografias, revistas, anotações de viagens e outros. [...] O painel de tendências é um compilado de informações, agrupadas de maneira agradável e de fácil identificação visual, para auxiliar o designer a perceber tendências para a estação. É através do painel de tendências que o designer pode visualizar quais os elementos de estilo poderá utilizar em sua coleção para que se apresente contextualizada com os demais lançamentos (IDEM, 2013, p. 81 e 82).
\end{abstract}

O último eixo de pesquisa é a Pesquisa de Tema de Coleção. Segundo Treptow (2013, p.83), "tema é a história, o argumento, a inspiração de uma coleção". A autora explica que "a partir da inspiração escolhida, [a pesquisa] reúne informações que possam ser usadas criativamente no desenvolvimento de coleção" (p. 72). Uma sugestão que deixamos aqui é que se aproveite a visão, elaborada a partir do cenário, para a delimitação do tema de coleção. Quanto mais afinado o tema estiver com o cenário existente ou previsto, mais chances de sucesso para a coleção.

Podemos ainda relacionar os tópicos do metaprojeto às fases seguintes da metodologia de Treptow. Por exemplo: os fatores tipológicos, formais e ergonômicos podem ser utilizados na fase do Design, para garantir que os produtos atendam às funções esperadas, sejam operativas, de suporte, de uso ou de estima.

Decidimos acrescentar um outro eixo de pesquisa à metodologia de Treptow, que pode ser de grande auxílio na etapa de promoção e comercialização apontada pela autora (da qual não tratamos anteriormente). Ela sugere algumas formas de lançamento e divulgação, tais como participação em feiras, releases de imprensa, desfile, catálogo, endosso de celebridades, vitrine e internet (TREPTOW,2013). Tudo isso será decisivo 
para a comercialização da coleção, e deve ser pensado concomitantemente com o desenvolvimento dos produtos.

Assim, sugerimos a criação do eixo Marketing no processo de pesquisas e desenvolvimento. Ele estaria relacionado ao sistema produto/design do metaprojeto, que segundo Moraes (2010), aproxima-se dos conceitos de design estratégico, e seria pensado paralelamente ao design dos produtos, em parceria entre as equipes de design e de marketing, para garantir a coerência entre o produto e o universo que o circunda. Assim, seriam planejados tanto o produto quanto sua comunicação, distribuição e os eventuais serviços disponibilizados ao cliente, além dos valores imateriais.

Como resultado das pesquisas, pode ser elaborado um painel de marketing composto por imagens que representem as propostas do sistema produto/design, tais como: ambientação da loja, cenários, iluminação, e demais aspectos do visual merchandising; comunicação visual do produto, sites, catálogos, publicidades em geral, etc. O painel deve refletir a "[...] unidade formal, harmonia visual, coerência entre as partes e a mensagem percebida (clareza na comunicação, significado e mensagem)" (MORAES, 2010, p.55), que serão buscadas na concepção da comunicação de marketing.

O último tópico do metaprojeto, que consideramos um dos mais importantes, é o de sustentabilidade socioambiental. Não o relacionamos a nenhum dos eixos de Treptow, pois acreditamos que ele deve permear todo o processo, deve ser uma preocupação constante. Assim, pode ser elaborado um painel imagético referente a ele, ou simplesmente abordar todas as pesquisas com o enfoque sustentável.

Moraes (2010, p.56) defende que "[...] o atual estágio em que se encontra a indústria mundial - entenda-se a rápida disseminação produtiva e o aumento significativo do número de consumidores - exige o empreendimento de outras ações em busca da preservação sustentável do meio ambiente". Ele reforça que o problema ambiental deixou de ser um problema local para se tornar mundial. Hoje é de fundamental importância a preocupação com o ciclo de vida dos produtos industriais, que vai desde a obtenção da matéria-prima, passando pela produção (muitas vezes poluente), seguida pelo uso e consumo, e chegando ao descarte.

Deve-se dar especial atenção a este tópico na fase do Design, momento em que são definidos muitos detalhes produtivos e funcionais dos produtos. Moraes (2010) sugere, além da preocupação constante com o ciclo de vida, que se priorizem materiais e 
processos de baixo impacto ambiental, e se exerça um design orientado para a sustentabilidade ambiental.

\section{Considerações Finais}

No processo de migração para o campo do design, identificamos um exagero nas estratégias de estilistas e designers, no sentido da autopromoção das suas práticas. Neste propósito, houve uma supervalorização da capacidade projetual, que legitima o designer como dominante no campo, e apresenta a equivocada idéia de que o estilista não segue uma metodologia para concepção de produtos para o vestuário. Entretanto, ao analisar a metodologia de Treptow, bastante utilizada hoje, e, sobretudo no momento transitório entre a formação em estilismo e em design, verificamos que, além de válida e legítima para o desenvolvimento de coleções de moda, ela apresenta também uma estrutura correspondente à estruturação básica das metodologias do design, sendo que apresenta especificidades importantes referentes à indústria da moda.

Ampliamos nossas análises, no sentido do aprimoramento da metodologia projetual e verificamos que a aplicação do metaprojeto enriquece o processo metodológico da moda, ampliando o universo de pesquisa e criando interrelações entre cada um dos eixos de pesquisa de Treptow. Neste sentido, acreditamos que a pesquisa, da forma como a autora sugere, pode ser enriquecida com a criação de um eixo de Marketing, bem como com a preocupação constante com a sustentabilidade, em cada um dos eixos.

Entendemos que esta análise, em especial a parte referente ao metaprojeto, pode gerar muitas outras possibilidades de aplicação que não foram aqui listadas. Por ser aberto, o metaprojeto se propõe a atuar de forma transversal, permeando todo o processo metodológico. Assim, muitas outras relações entre os tópicos metaprojetuais e a metodologia da moda ainda podem ser estabelecidas.

\section{Artigo recebido em Julho de 2015. Aprovado em Setembro de 2015 DOI:http://dx.doi.org/105965/1982615x08172016091}

\section{Referências}


BONADIO, M.C. A produção acadêmica sobre moda na pós-graduação strictu sensu no Brasil. Iara: Revista de Moda, Cultura e Arte. São Paulo. V.3. No. 3. Dez.2010. BOURDIEU, P. Algumas propriedades dos campos. In: P. Questões de sociologia. Rio de Janeiro: Marco Zero, 1983.

BÜRDECK, B. E. História, teoria e prática do design d e produtos. Tradução Freddy Van Camp. São Paulo: Edgard Blücher, 2006.

CHRISTO, D. Estutura e funcionamento do campo de produção de objetos do vestuário no Brasil. 2013. 146 f. Tese. (Doutorado em Design) - Pontifícia Universidade Católica, Rio de Janeiro, 2013.

CHRISTO, D. CIPINIUK, A. Estrutura e funcionamento do campo de produção de objetos do vestuário no Brasil. Fortaleza: UFC, 2013. Anais Colóquio de Moda. LIPOVETSKY, G. O império do efêmero. São Paulo: Companhia das Letras, 1989. LÖBACH, B. Design Industrial: bases para a configuração dos produtos industriais. São Paulo: Blucher, 2001. MINISTÉRIO DA EDUCAÇÃO. Relatório da consulta textual - curso > nome do curso. Disponível em <www.emec.mec.gov.br>. Acesso em março de 2014. MORAES, D. Metaprojeto: o design do design. São Paulo: Blucher, 2010. Metaprojeto como Modelo Projetual. In: MORAES, D.. DIAS, R. A. BOM

CONSELHO R. Método. Cadernos de Estudos Avançados em Design. Barbacena, MG: EdUEMG, 2011.

PIRES, D. Design de Moda - Olhares diversos. Rio de Janeiro: Estação das Letras, 2008 .

QUEIROZ, C. Do Estilismo ao Design: Os currículos do bacharelado em Moda da Universidade Federal do Ceará. 2014. 195 f. Tese (Doutorado em Educação) Universidade Federal do Ceará, Ceará, 2014.

SOUZA, G. O espírito das roupas - a moda no século XIX. São Paulo: Companhia das Letras, 1987.

TREPTOW, D. Inventando Moda: planejamento de coleção. 5. ed. São Paulo: Edição da Autora, 2013.

VASCONCELOS, L. et al. Um Modelo de Classificação para Metodologias em Design. In: $9^{\circ}$ Congresso Brasileiro de Pesquisa e Desenvolvimento em Design. São Paulo: Blücher e Universidade Anhembi Morumbi, 2010. Disponível em: 


\section{ModaPalavra E-periódico}

<http://blogs.anhembi.br/congressodesign/anais/artigos/69866.pdf >. Acesso em: 16 Ago. 2015. 